\title{
Food Safety and Aflatoxin Control
}

\author{
Philippe Villers ${ }^{1}$ \\ ${ }^{1}$ President, GrainPro, Inc., Concord MA, USA \\ Correspondence: Philippe Villers, GrainPro, Inc., 200 Baker Ave, Suite 309, Concord MA, USA. Tel: \\ 1-978-371-7118. E-mail: pvillers@grainpro.com
}

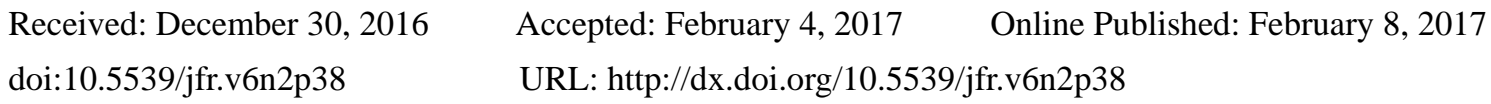

\begin{abstract}
This paper examines the prevention of the exponential growth of aflatoxin occurring in multi-month, postharvest storage in tropical countries, with examples from field experience and scientific data. Four approaches to modern, safe, postharvest storage methods are described, the most successful being the use of flexible, UltraHermetic ${ }^{\mathrm{TM}}$ airtight structures that create an unbreatheable atmosphere (low oxygen, high carbon dioxide) through insect and microorganism respiration alone, without use of chemicals, fumigants, vacuum, or refrigeration.

The increase in aflatoxin levels during multi-month, postharvest storage is a serious health hazard affecting several major crops. During postharvest crop storage by conventional methods in tropical conditions, molds existing within crops can produce aflatoxin levels many times greater than at harvest, often vastly exceeding the international safety standards of $20 \mathrm{ppb}$ (parts per billion). For example, field data from Mali documents that during just two months of conventional peanut storage, average aflatoxin levels rose $200 \%$. In Uganda, aflatoxin levels in conventionally stored maize rose $300 \%$ in three months. By contrast, laboratory and field data from Mali and Uganda show that the organically modified atmosphere created using various forms of sufficiently hermetic (airtight) storage containers (ranging from $25 \mathrm{~kg}$ to 1000 -tonne capacity) prevents the exponential growth of aflatoxin-producing molds in various grains, peanuts, and seeds.
\end{abstract}

Keywords: aflatoxin, Cocoon ${ }^{\mathrm{TM}}$, GrainSafe ${ }^{\mathrm{TM}}$, grain storage, hermetic, pesticide-free, postharvest, SuperGrainbag ${ }^{\mathrm{TM}}$, UltraHermetic

\section{Consequences of High Aflatoxin Levels}

Dr. Williams of the University of Georgia, USA, describes aflatoxins as follows: "Aflatoxin (AF) is a toxin produced by fungi acting on staple crops (like maize, rice, cassava and peanuts) that constitute a large part of the diet of people living in developing countries. For these people, there is little management of food quality and they are at risk of uncontrolled exposure to AF. In the US and many other countries, human foods must have less than $20 \mathrm{ppb}$ (the threshold for cumulative genetic toxicity) but the threshold for diagnosable symptoms of acute aflatoxicosis (jaundice, vomiting, abdominal pain, hemorrhage, pulmonary edema and death) is much higher. Veterinary toxicology has shown chronic, moderate exposure results in suppressed immunity, nutrition and increased infectious diseases. These results from animal studies are being found relevant to humans living in developing countrie (Williams et al., 2004).

Since the health consequences of high levels of aflatoxins (Aspergillus flavus and Aspergillus parasiticus) are widely recognized as a major problem, the international community and many individual countries have set strict limits on acceptable levels of aflatoxin - most commonly 10-20 parts per billion (ppb). In practice these limits are often greatly exceeded with serious health effects.

In human beings, high aflatoxin levels depress the immune system, thereby contributing to many health problems ranging from cancer and susceptibility to HIV, to stunted growth among children. In African countries, Dr. Williams cites a sampling survey of several local markets showed that in $40 \%$ of the commodities found that levels of aflatoxins in foods exceeded the international standard of 10 to $20 \mathrm{ppb}$, putting an estimated 4.5 billion people in developing African countries at risk. A cross-sectional study conducted in Ghana and also cited by Dr. Williams showed that the immune systems of recently HIV-infected people had above-median levels of aflatoxins and that "people with a high aflatoxin biomarker status in the Gambia and Ghana were more likely to have active malaria." Small holder farmers were particularly affected: "A major area of neglect and opportunity is foods stored by small farmers for their own consumption. A very common consequence of quality control in 
markets is for farmers to retain, for their own use, grains that would reduce the price offered in the market place. Studies of peanuts in local storage facilities show a steady increase in contamination levels and these differences are observed in the cyclical variation in the biomarkers of rural African people." (Williams, 2011).

At an October 2016 meeting of the Partnership for Aflatoxin Control in Africa (PACA), Ugandan President, H.E. Yoweri Museveni called for a collective effort among African countries to address aflatoxin challenges as they are a major health risk and impede the agricultural and trade sectors of the continent. President Museveni pointed to diseases such as cancer, pneumonia and Hepatitis B, among other illnesses that could be caused by consuming foods contaminated by aflatoxins (Museveni, 2016).

In the case of domestic animals, various studies in Africa have attributed severe health impact to high aflatoxin levels. Excessive aflatoxin levels also cause failure to thrive (or even death) in farm animals such as chickens, turkeys and cattle. Per Dr. Oladele Dotun, a Veterinarian at the Animal Care Laboratory in Nigeria, research has shown that aflatoxins cause infertility, abortions, and delayed onset of egg production in birds as well as sudden losses in egg production. Furthermore, loss of appetite, skin discoloration or even yellowish pigmentation on skin can be observed in fish (Oladele, 2014).

In 2014, the Global Forum for Innovations in Agriculture (GFIA) convened a high-level meeting in Abu Dhabi, UAE. There, Frank Rijsberman, the CEO of the Global Agricultural Research Partnership (CGIAR Consortium), concluded on the basis of a Benin study (Gong et al., 2004) that post-weaning exposure to aflatoxin has impaired growth in children and is costing African farmers over $\$ 450$ million USD per year in lost exports (Rijsberman, 2014).

In 2010, $10 \%$ of the Kenyan maize crop was condemned because of excessive aflatoxin levels. In the same year, a Kenyan laboratory tested 130 maize samples, out of which only 47 samples had aflatoxin levels less than 10 ppb. The highest level of aflatoxin recorded in that year was 830 ppb (FAO, 2011).

In addition to health problems, quantitative losses from insects, rodents and molds in grains such as maize conventionally stored for many months can and often do exceed 25\%. A World Bank report shows postharvest losses for maize in Eastern Africa (Figure 1).

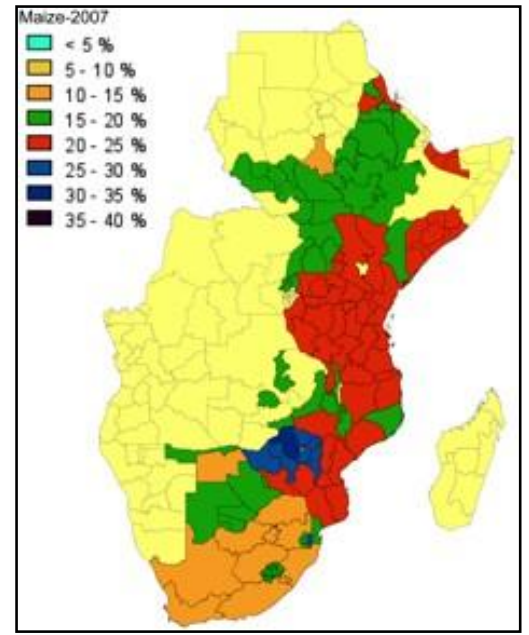

Figure 1. Estimated percentage of cumulative postharvest weight loss from production of maize in East and Southern Africa for 2007 (Zorya et. al., 2011)

\section{Preventing Growth of Aflatoxins}

Aflatoxins produced by strains of the Aspergillus fungus (Aspergillus flavus and Aspergillus parasiticus) are now a well-documented threat to public health, especially in tropical climates. Much work has been done in the field to control aflatoxin levels, with some useful results. To date, partial solutions such as selective breeding of crops for greater resistance, modified growing conditions, and biological controls have shown positive effects.

Biological competition, through use of molds that are similar to aflatoxin-generating molds but do not generate aflatoxins, has been shown to be particularly important. In the field, these molds can be used to outcompete the aflatoxin producing molds. A product called AflaSafe ${ }^{\mathrm{TM}}$, which uses this competitive approach, is now used in eleven African countries (Bandyopadhyay et al., 2016). 
However, postharvest storage is the most overlooked stage for effectively preventing aflatoxin growth. In hot, humid climates, long term conventional storage can produce exponential growth of aflatoxins as shown in Table 1. It shows that restricting the increase in aflatoxin levels during both drying and long-term storage is a major challenge, particularly in hot and humid conditions. Table 2, following, shows field data from Mali where the aflatoxin in peanuts increased on average $200 \%$ in just two months of conventional storage (Gou, 2013). In addition, Figure 2 (De Bruin, et al., 2014) shows the exponential growth of fungus (mold) density at relative humidity above $65 \%$. Such levels are common in the hot humid climates found in Africa, Asia and Latin America.

Table 1. Effect of interventions on aflatoxin levels (ppb) in peanuts for Drobonso Village, Ashanti Region, Ghana, 2014/2015 major season (Appaw, 2016).

\begin{tabular}{|c|c|c|c|c|c|}
\hline & $\begin{array}{c}\text { Field } \\
\text { (Harvesting Stage) }\end{array}$ & $\begin{array}{r}\text { Drying } \\
\text { (Ground vs }\end{array}$ & $\begin{array}{l}\text { tage * } \\
\text { Tarpaulin) }\end{array}$ & $\begin{array}{r}\text { Storage } \\
\text { (Poly sac vs H }\end{array}$ & $\begin{array}{l}\text { Stage }^{+} \\
\text {ermetic Bag) }\end{array}$ \\
\hline Practice & Aflatoxin level & Aflatoxin level & $\%$ Reduction & Aflatoxin level & $\%$ Reduction \\
\hline $\begin{array}{c}\text { Farmer } \\
\text { (conventional) }\end{array}$ & Not detected & $\begin{array}{c}4.68-51.90 \\
(38.24 \text { average })\end{array}$ & \multirow{2}{*}{$\begin{array}{c}50-97 \\
(85 \% \text { average })\end{array}$} & $\begin{array}{r}6.61-438.79 \\
(133.22 \text { ave. }) \\
\end{array}$ & \multirow{2}{*}{$\begin{array}{c}86-99 \\
\text { (95\% average) }\end{array}$} \\
\hline $\begin{array}{l}\text { Improved } \\
\text { (hermetic) }\end{array}$ & Not detected & $\begin{array}{c}1.49-21.21 \\
(5.94 \text { average })\end{array}$ & & $\begin{array}{c}0.88-31.36 \\
(10.89 \text { average })\end{array}$ & \\
\hline
\end{tabular}

Aflatoxin analysis done using HPLC based on AOAC official methods.

*Solar dried to reach average moisture content of $6.25 \%$.

${ }^{+}$Storage approximately 9 months at ambient temperature.

Table 2. Increased aflatoxin levels in peanuts during conventional storage in farmers' fields in Mali.

\begin{tabular}{llll}
\hline \multirow{2}{*}{ Village } & \multicolumn{3}{c}{ Aflatoxin content (ppb) } \\
\cline { 2 - 4 } & At harvest & 1 month in storage & 2 months in storage \\
\hline Bamba (5) & 101.3 & 168.9 & 275.5 \\
Gouak (5) & 61.4 & 118.0 & 174.7 \\
Kolokani (5) & 119.2 & 352.6 & 400.0 \\
Sido (5) & 53.7 & 93.6 & 166.2 \\
\hline
\end{tabular}

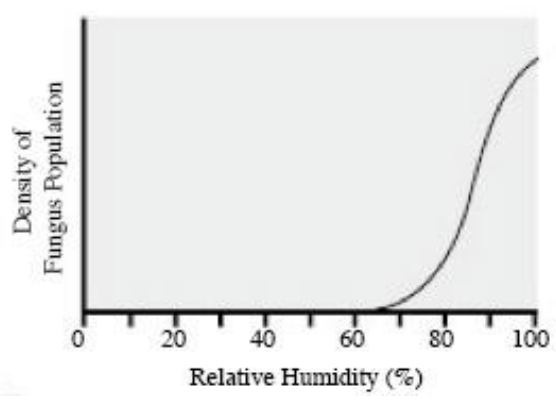

Figure 2. Typical fungus density versus humidity

\section{Key Susceptible Crops}

The crops that most commonly exhibit excessive levels of aflatoxin in hot, humid climates include maize, wheat, peanuts, rice, millet and cassava. As stated earlier, in Kenya in 2010, maize suffered catastrophic contamination due to excessive aflatoxin levels; $10 \%$ of the Kenyan maize crop was condemned for aflatoxin levels exceeding international standards (20ppb). In some cases, the product was reported to cause deaths (FAO, 2011).

\section{Forms of Aflatoxin Control in Storage}

\subsection{Non-Chemical Methods}

What can be done to protect susceptible commodities during storage? One very costly approach is refrigeration 
or air conditioning, which can inhibit significant growth of aflatoxins by keeping down both humidity and temperature levels. It has been used successfully in some countries, including in Japan for storing rice. However, this method cannot be successfully applied everywhere due to both the cost and uncertainty of available electrical power. A new, and still experimental, method has been introduced by the Ozonextrade Kft. company in Hungary (Figure 3) using a small ozone generator to destroy microbes, insects and molds in large metal silos (Lippai, 2016). Ozone, however, is not compatible with storage in many plastics, including PVC.

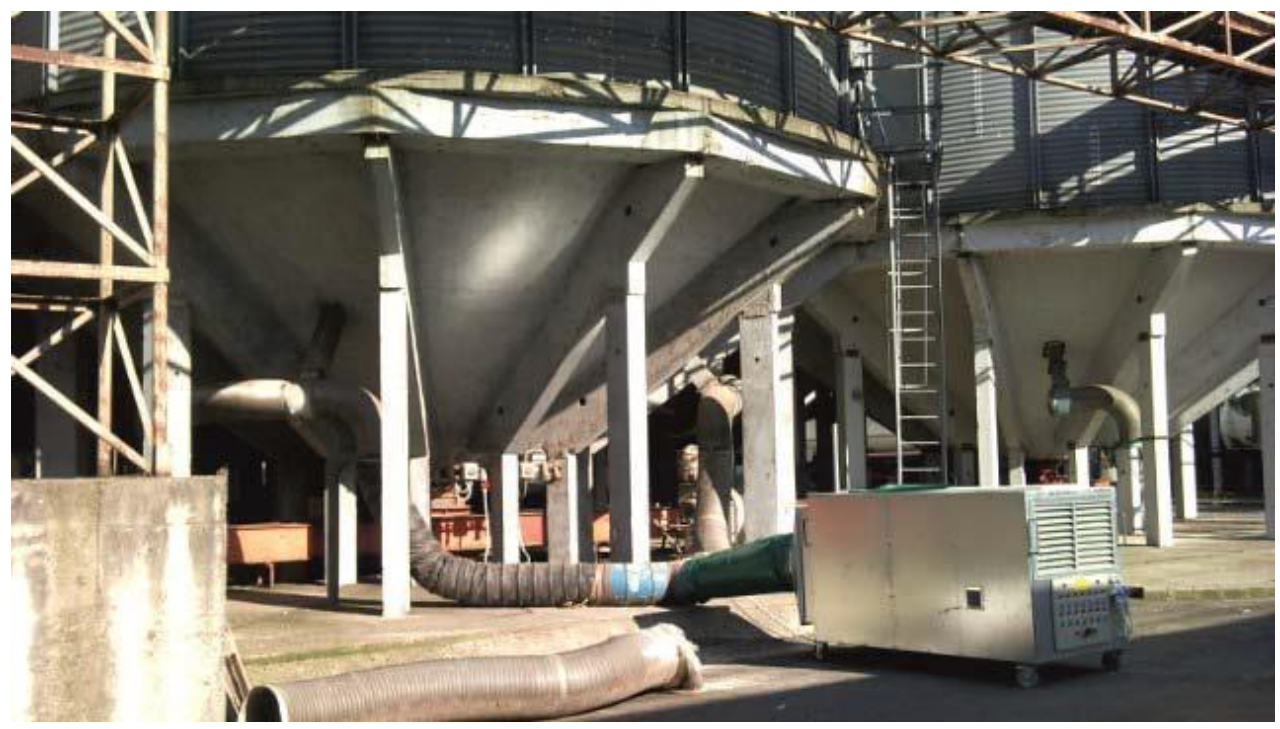

Figure 3. Ozone Generator, courtesy of Ozonextrade, Hungary

\subsection{Chemical Methods}

A chemical treatment was described by Lunven of FAO, as follows: "Chakrabarti showed that aflatoxin levels could be reduced to less than $20 \mathrm{ppb}$ using separate treatments with 3 percent hydrogen peroxide, 75 percent methanol, 5 percent dimethylamine hydrochloride or 3 percent perchloric acid. These treatments, however, induced losses in weight and also in protein and lipids. Other methods include the use of carbon dioxide plus potassium sorbate and the use of sulphur oxide." Lunven also noted another process that had received some attention, namely the use of calcium hydroxide, a chemical used for lime cooking of maize: "Studies have shown a significant reduction in aflatoxin levels, although the extent of reduction is related to the initial levels. Feeding tests with moldy maize treated with calcium hydroxide have shown a partial restoration of its nutritional value" (Lunven, 1992).

However, as stated in the FAO report, "To date, no chemical or additive method has gained general acceptance. Concerns about using chemicals or additives is still growing, encouraging the expanded use of methods that have no contamination potential, and methods that cannot harm consumers, producers, or warehouse personnel." (Lunven, 1992). One example is flexible, UltraHermetic storage with or without the use of carbon dioxide as an accelerant to create controlled humidity, low oxygen, with a high carbon dioxide, modified atmosphere.

\subsection{Biological Method Using GMO Technology}

Biological methods include using GMO technology such as providing insect resistance using Bacillus thuringiensis (Monda, 2016). The focus on resistance to insects is due to the high correlation existing between insect damage and aflatoxin contamination. GMO technological approaches to aflatoxin management mainly have focused on expression of recombinant insecticidal proteins from Bacillus thuringiensis, expression of antifungal peptides and proteins and the use of Host-Induced Gene Silencing technology. The use of Bacillus thuringiensis toxin technology against the European corn borer has enabled a reduction of aflatoxin levels in maize (Monda, 2016).

\subsection{UltraHermetic Storage Method}

An increasingly popular and inexpensive alternative method for controlling aflatoxin growth during multi-month storage is through use of flexible, UltraHermetic storage containers. This storage technology relies on creating a condition such that insect plus microflora respiration, and sometimes respiration of the commodity itself, is 
greater than residual intake of oxygen through ultra-low permeability container material. In some cases initial $\mathrm{CO}_{2}$ injection can be added in order to speed up the process of reducing oxygen levels to an unbreatheable level, typically $3 \% \mathrm{O}_{2}$. On a commercial basis, UltraHermetic storage is an environmentally friendly solution now being used in more than 110 countries. It is lightweight, flexible, and available in a growing variety of forms to store $25 \mathrm{~kg}$ to 1000 -tonne capacity Cocoons ${ }^{\mathrm{TM}}$ and SuperGrainbags ${ }^{\mathrm{TM}}$.

Growth of aflatoxins in this type of storage is largely inhibited, by both oxygen deprivation and preventing the ingress of humidity. This denies aflatoxin producing molds what they need to grow, namely oxygen and high relative humidity. The molds themselves survive but grow very slowly.

In most other commodities stored hermetically, respiration alone remains sufficient to deplete oxygen levels. In the special case of ground nuts (peanuts), however, it has been found that the level of insect infestation is often too low to prevent significant growth of aflatoxins through microflora and insect respiration alone, before oxygen levels approach an unbreathable $3 \%$. To combat this, two supplemental methods have proved successful. One method is to introduce $\mathrm{CO}_{2}$ immediately after closing the container to drive out the air and fill it largely with $\mathrm{CO}_{2}$ - typically up to $90 \% \mathrm{CO}_{2}$ or more. To accomplish the same goal in farm settings, the other method is to insert into the storage container the readily available small commercial oxygen absorbers "sachets" such as seen in Figure 4. These absorb available oxygen, typically in less than a day. In the case of ground nuts (peanuts), this method also creates the desired low-oxygen atmosphere much faster than can be done using insect and microflora respiration alone.

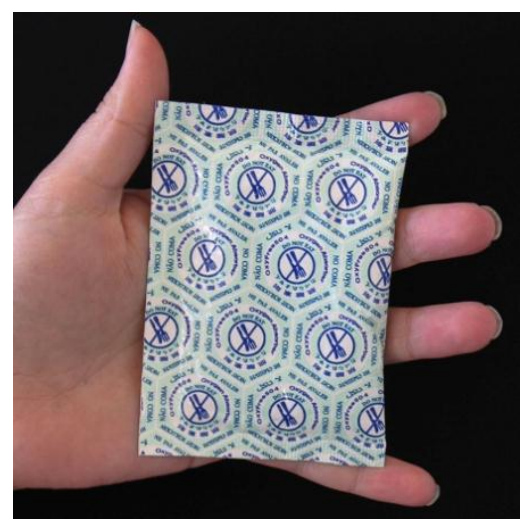

Figure 4. 1,000cc-capacity oxygen absorber

\section{Field Data on the Control of Aflatoxin}

In recent years, several controlled experiments have shown the advantage of hermetic storage in preventing growth of aflatoxins during storage. The most recent example is the recent USAID study previously cited in Section 1 and shown in Table 1.

In addition, a Millenium Village study in Ruhira, Uganda (Figure 5) shows the difference in growth of aflatoxin levels between conventional and UltraHermetic storage (De Bruin, T., Villers, P., Navarro, S., 2014). This is similar to the data on peanuts previously cited in Section 2 and Table 1. 


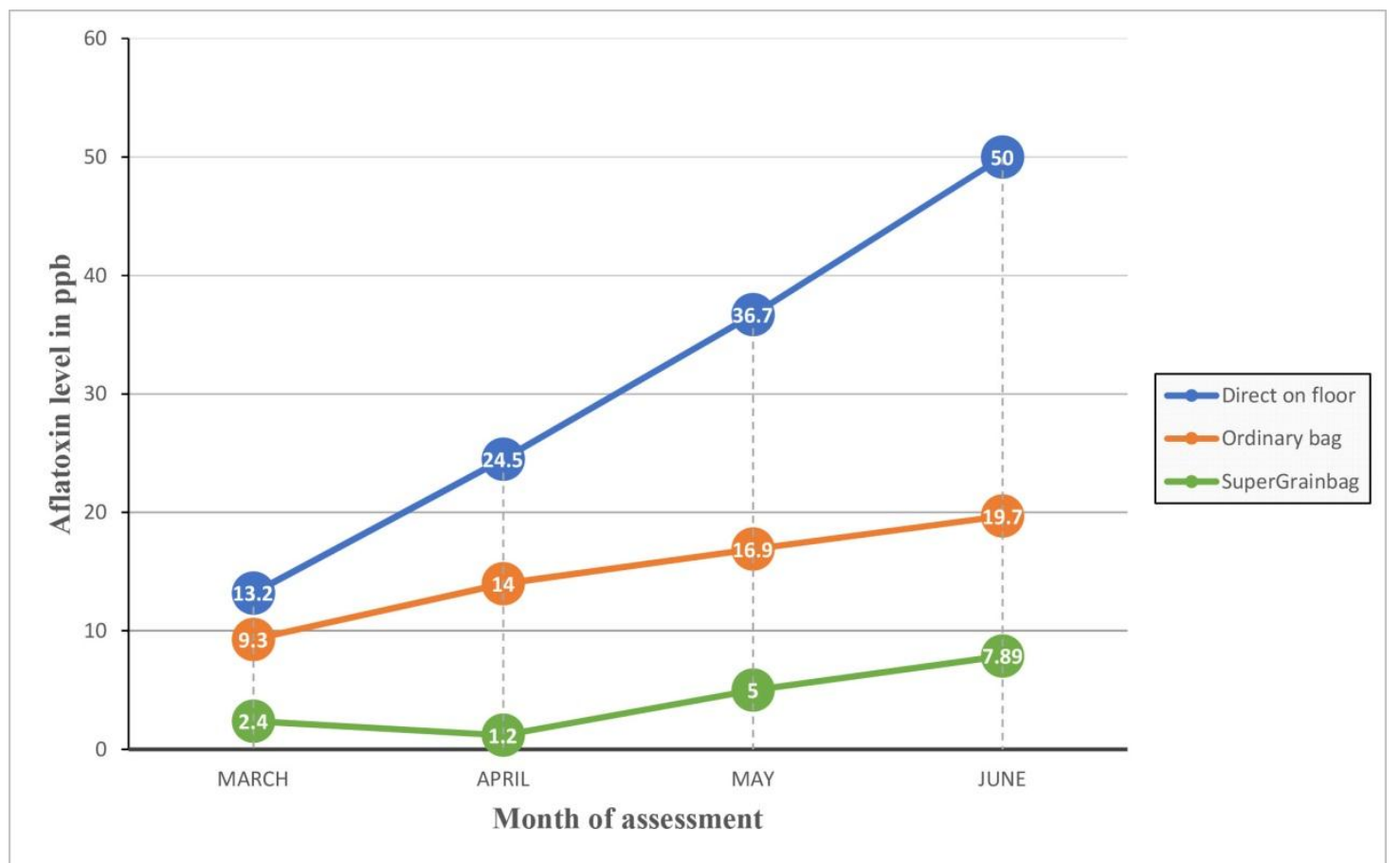

Figure 5. Monthly aflatoxin concentration in maize stored in different storage conditions in Ruhira, Uganda,

Millennium Villages study, 2013

\section{Proper Drying of Grains}

For successful use of UltraHermetic storage as well as for other storage methods, crops must be adequately dried, typically to a point below their "critical moisture level" (in equilibrium with $65 \%$ relative humidity). However, the drying period is often a source of growth in aflatoxins. Long drying cycles or re-wetting because of rain or dew encourage growth of aflatoxins both directly and indirectly - directly because of long drying exposure, and indirectly because extended drying and rewetting creates more broken kernels (i.e., "brokens") which make the spread of aflatoxins far more rapid. This can be prevented in several ways, including by thermal dryers using fossil fuels such as wood or petroleum products; these allow the commodity to dry more rapidly than it does when solar energy is used. However, for high value crops such as coffee or seeds, care must be taken not to exceed the maximum safe temperature to avoid product deterioration: $40^{\circ} \mathrm{C}$ in the case of parchment coffee, and $45^{\circ} \mathrm{C}$ for coffee cherries.

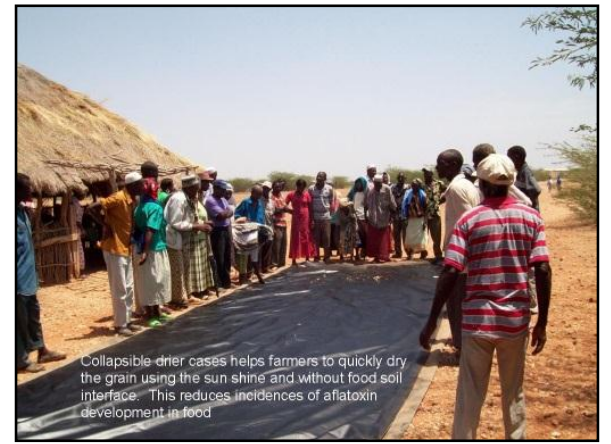

Figure 6. First generation Solar Dryer (courtesy of GrainPro, Inc.)

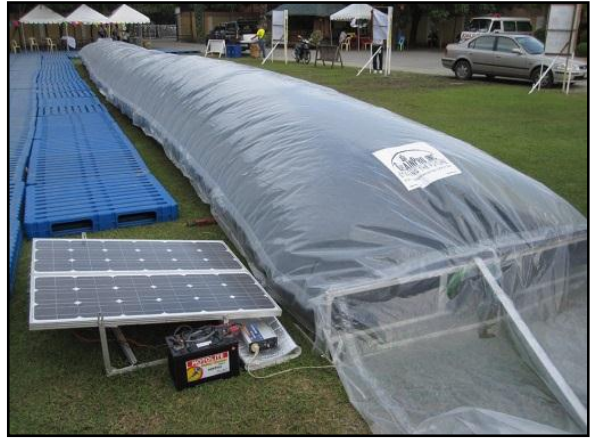

Figure 7. Solar Bubble Dryer with optional, solar panels (courtesy of GrainPro, Inc.) 
The product being dried can be easily contaminated during sun drying, which is often done on patios or on paved or unpaved roads. Further, drying is slowed on patios or roads, particularly when there is dew in the morning or rain, because the porous surface on which the product is being dried must be dried along with the commodity. Recently, use of portable solar dryers such as the Collapsible Dryer Case (CDCTM) (Figure 6) and the Solar Bubble Dryer (SBD ${ }^{\mathrm{TM}}$ ) (Figure 7) have resolved this problem by separating the underlying surface such as a patio or road from the grains being dried with an impermeable, coated, woven polyethylene surface, which provides both a moisture barrier and a thermally insulated surface. When there is rain or heavy dew, the simpler Collapsible Dryer Case ${ }^{\mathrm{TM}}$ (CDC) dryer is folded back on itself manually with the commodities still inside, and is closed, awaiting the end of the rain.

The more advanced Solar Bubble Dryer ${ }^{\mathrm{TM}}$ (SBD), using a greenhouse approach, prevents rain from rewetting the crops by enclosing it in a transparent "bubble" which also speeds drying from solar gain or the so-called "greenhouse effect." These relatively simple solar dryers are becoming increasingly popular because they are relatively low cost to purchase and operate. In addition, they are both environmentally friendly and easily moved to new locations.

\section{Seed Storage}

Seeds of all types also benefit from hermetic storage. Maintaining seed germination capability for multiple months is difficult in tropical climates unless one uses costly, energy intensive, air conditioning or refrigeration. Without refrigeration, germination rates can drop dramatically, as shown in Figure 8.

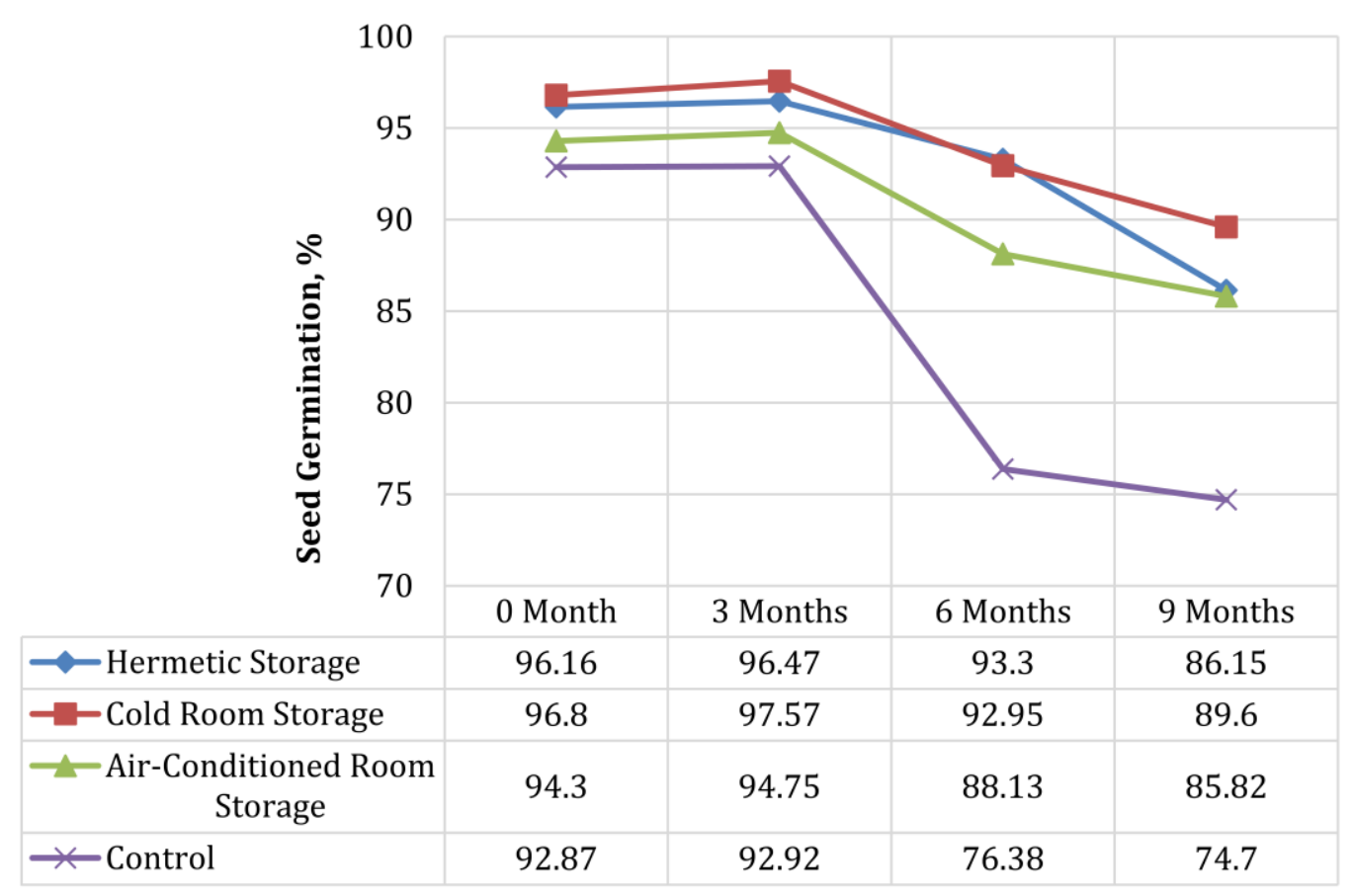

Figure 8. Preservation of rice paddy seed using hermetic and low temperature storage technologies.

(Sabio, Dator et al., 2006)

Seeds in UltraHermetic storage maintain high levels of germination capacity, typically for at least a year (85\% is required for certified seed). For this reason, hermetic storage is now used increasingly for seed storage, particularly in the developing world, as an equivalent alternative to the older refrigeration techniques with their higher energy requirements.

Figure 9 shows cotton seed germination when stored in a cold room, as contrasted with hermetic storage in Cocoons and conventional (unprotected) storage in jute bags over a 12-month period. 


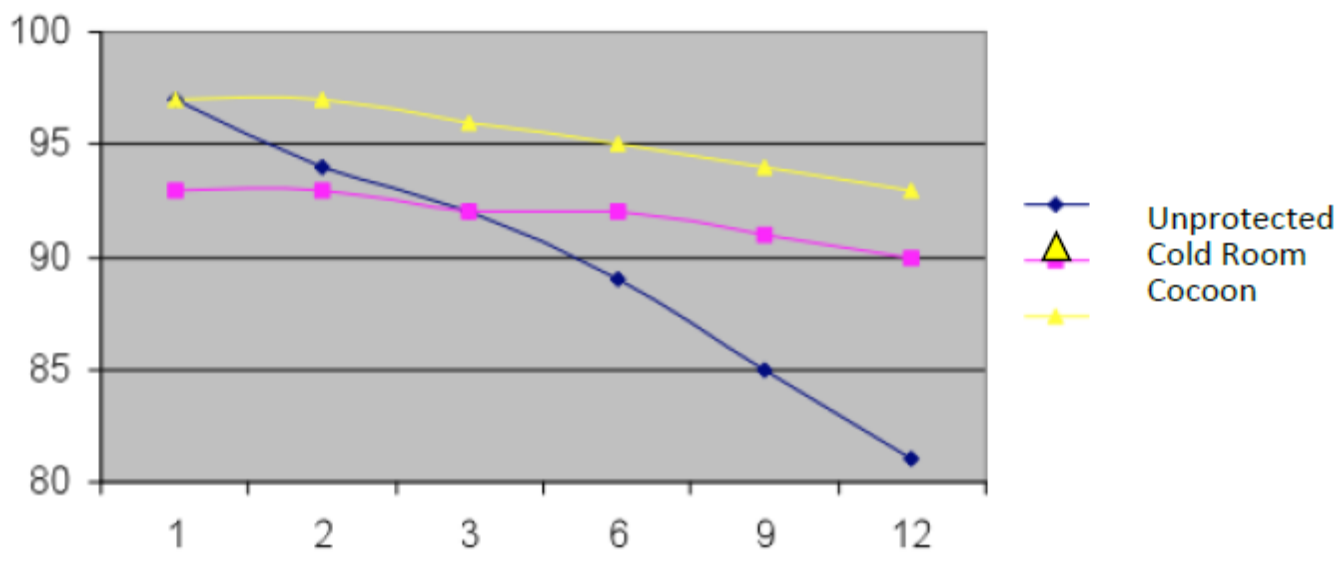

Figure 9. Cotton seed percent germination for 12-month storage, Peru, 2012 (courtesy Bayer Crop Science)

\section{Other Uses of Hermetic Storage \& Available Forms}

Ultrahermetic storage is important for aflatoxin reduction in multi-month storage, but it also fills other needs. By design it is sufficiently airtight so that insect respiration rate from both the insects and microflora that infect all grains is higher than residual leakage of air into the UltraHermetic container. Typical values achieved for permeability to oxygen in smaller UltraHermetic containers are $2 \mathrm{cc}$ to $4 \mathrm{cc} / \mathrm{m}^{2} /$ day and for water vapor $2 \mathrm{gm} / \mathrm{m}^{2} /$ day. Not only do all insect life forms-from eggs to adult-die through asphyxiation, but the commodity is protected from humidity entering. Commodities such as milled rice and bran that otherwise are very difficult to store can now be safely held for months without developing rancidity due to oxidation.

The advantage of UltraHermetic bags in man-portable sizes is their greater airtightness with ultra-low leakage rates for oxygen typically 2 to $4 \mathrm{cc} / \mathrm{m}^{2} /$ day. The bags are superior to ordinary plastic bags of the same thickness $(0.078 \mathrm{~mm})$, which have typically a permeability to oxygen of $2,000 \mathrm{cc} / \mathrm{m}^{2} /$ day because they have a special high resistance barrier layer sandwiched between two polyethylene layers. Nonetheless, despite the higher permeability, in some applications by using two plain high-density polyethylene $0.078 \mathrm{~mm}$ bags, one inside the other, commercially useful results have been obtained for a variety of crops. The most widely known example of this is the PICS bag developed by Purdue University initially for cowpea storage, but now used for several commercially important crops. (Sudini, et al., 2014, Williams, Baributsa, \& Woloshuk, 2014)

Both UltraHermetic and less hermetic bags have excellent low permeability to water vapor, typically 1 to 2 $\mathrm{gm} / \mathrm{m}^{2} /$ day or less. Other users have used plain polyethylene bags plus a modest vacuum level, but the vacuum levels reached do not approach lethal oxygen levels (normally $3 \%$ oxygen) and have not been found to perform better than UltraHermetically sealed bags. (Borem, 2013)

Because of wide variation in storage needs, the size and form of UltraHermetic storage in current use covers a broad range. Depending on the application, UltraHermetic storage forms can range from man-portable bags with capacities from 25 to 100 kilograms (Figure 10) to 1.4 tonne SuperGrainbags or Cocoons ${ }^{\mathrm{TM}}$ with large scale capacities from 5- to 1,000-tonnes of bagged grains. In cases where the product needs to be very portable, the SuperGrainbag ${ }^{\circledR}$ (SGB) from $25 \mathrm{~kg}$ to $100 \mathrm{~kg}$ capacity is in wide commercial use; over 2 million were delivered last year.

Figure 10 shows maize as sold in Nigeria raised and sold by a contract farming project known as Babban Gona in Kanu State, where an aggregation of 8,000 small farmers store maize in 50kg SuperGrainbags. Affixed with the label "Low Aflatoxin Maize." Many of the bags at Babban Gona are later used for commercial baby food. 


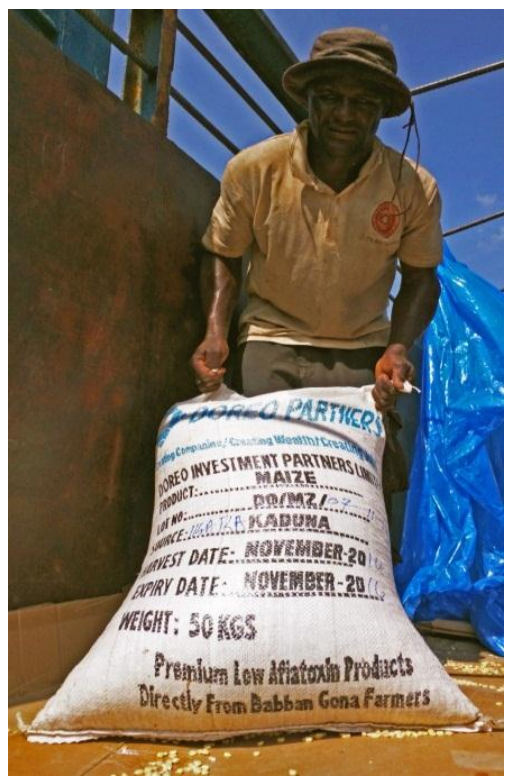

Figure 10. 50-kg SuperGrainbag liner inside a protective outer bag (courtesy Babban Gona,

Nigeria)

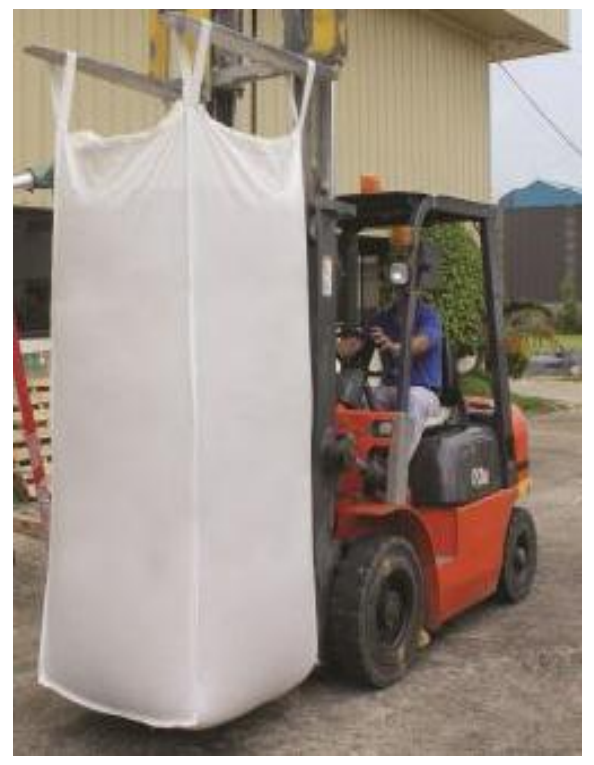

Figure 11. 1.4 tonne SuperGrainbag Ocean (courtesy GrainPro, Inc.)

The 1.4-tonne capacity SGB Ocean ${ }^{\mathrm{TM}}$ (Figure 11) and the GrainSafe $2^{\mathrm{TM}}$ (Figure 12) provide capability for continuous loading and unloading in bulk via input and output funnels without destroying the container's hermeticity. The GrainSafe ${ }^{\mathrm{TM}}$ is used for storage of bulk commodities and allows continuous in and out. Figure 12 also shows the range of some other commonly used UltraHermetic storage units.

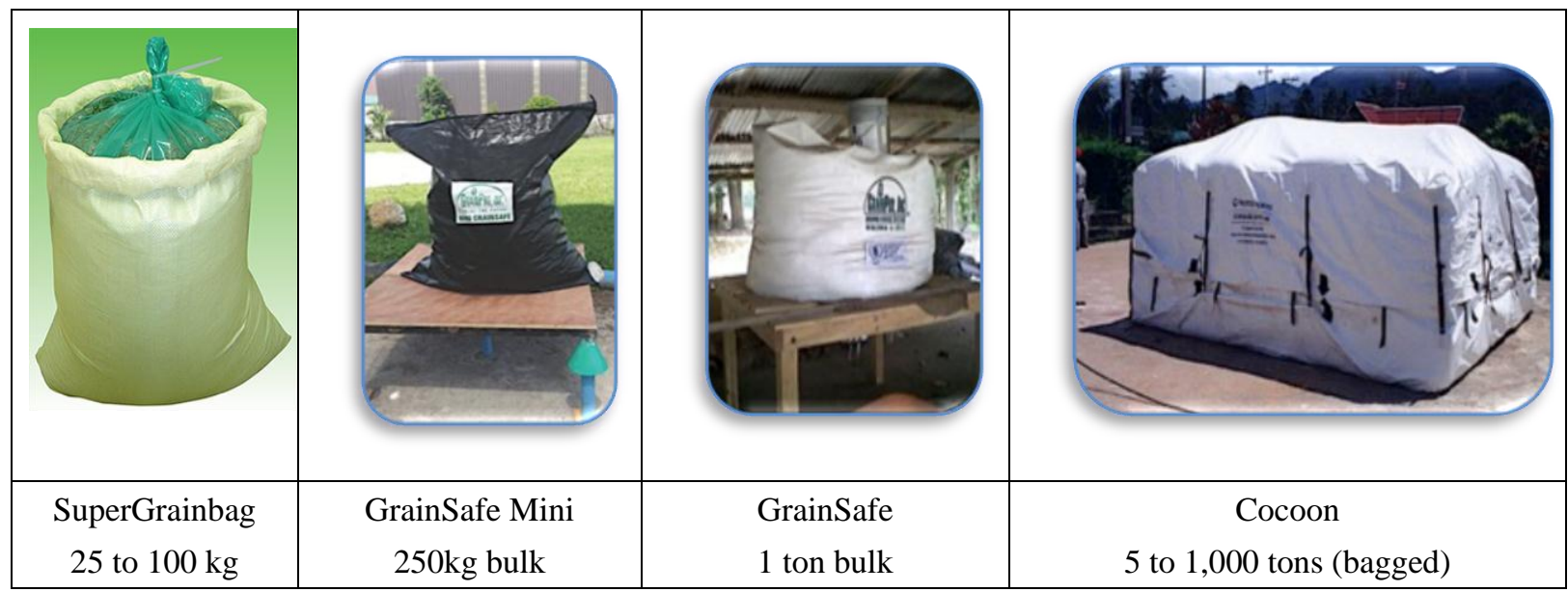

Figure 12. Hermetic storage capacities ranging from 25 kilos to 1000 tonnes. (GrainPro, Inc.)

There is already considerable literature on other benefits obtained from UltraHermetic storage (De Bruin, T., Villers, P., Navarro, S., 2014). These include the preservation of quality as well as prevention of quantitative losses caused by infesting insects, or additional weight loss due to change in moisture content. In the case of coffee, for example, the quality of green coffee beans is maintained for up to a year as measured by cupping tests. In the special case of coffee, insect infestation alone is small, and does not greatly reduce $0_{2}$ levels. The addition of $\mathrm{CO}_{2}$ has only minor benefit, showing that in some specific cases hermetic storage is sufficient to maintain quality without requiring low $\mathrm{O}_{2}$ levels. Table 3 shows the small difference between normal UltraHermetic storage of coffee and addition of $\mathrm{CO}_{2}$. 
Table 3. Mean values of the overall cupping score (indicates quality) of the coffee beans after 12-months of storage (Borem et al., 2013)

\begin{tabular}{lll}
\hline Big-bag (1-tonne hermetic) & Position & Score \\
\hline With $\mathrm{CO}_{2}$ & Upper & $80.00 \mathrm{a}$ \\
With $\mathrm{CO}_{2}$ & Middle & $80.80 \mathrm{a}$ \\
Without $\mathrm{CO}_{2}$ & Upper & $78.09 \mathrm{a}$ \\
Without $\mathrm{CO}_{2}$ & Middle & $78.06 \mathrm{a}$ \\
GrainPro (SuperGrainbag, 69kg, no $\mathrm{CO}_{2}$ ) & Hermetic only & $78.98 \mathrm{a}$ \\
Jute sack alone & Jute sack & $73.03 \mathrm{~b}$ \\
\hline
\end{tabular}

In other commodities, such as cocoa, milled rice or various nuts, hermetic storage also prevents the significant growth of free fatty acids (and therefore, rancidity) for periods of up to a year. Grains and other dry commodities must be preserved with little loss in quality and low aflatoxin levels to be able to export to such major markets as the EU.

A series of controlled experiments run in Brazil compared the effect of different green coffee storage methods, measuring "sensory analysis" after one year's storage (Figure 13). (Borem, 2016) UltraHermetic storage (referred to as "paper + high barrier") with or without anti-fogging agent and $\mathrm{CO}_{2}$ did best, with no statistically significant difference. The "a" label on some columns in Figure 13 indicates there is no statistical difference among them. Vacuum packaging and injection of $\mathrm{CO}_{2}$ resulted in a slightly lower (but again, not statistically significant) sensory analysis score, which includes cupping tests. Plain jute or paper storage without high barrier performed much worse. Use of paper vs. jute as an outer protective bag made no difference.

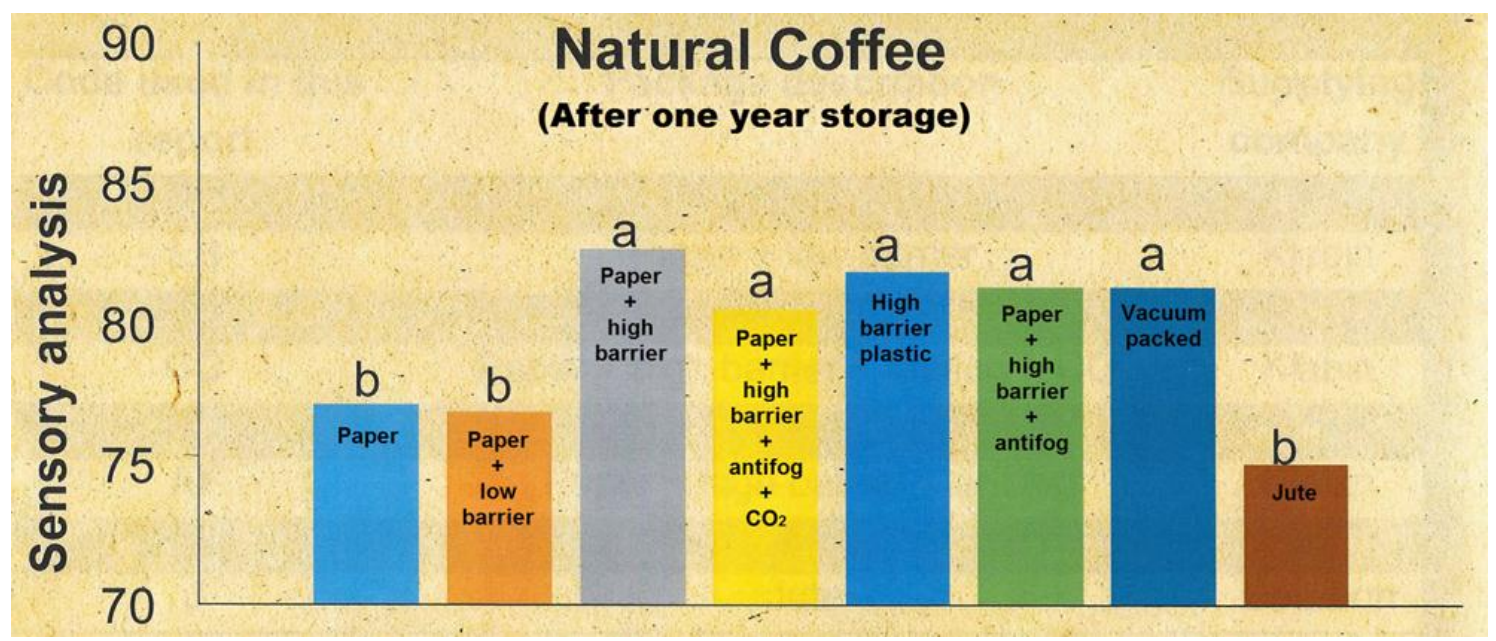

Figure 13. Sensory analysis for different coffee storage methods, measured after 12-months of storage (courtesy Prof. Flavio Meira Borem, Universidade Federal de Lavras, Lavras - Minas Gerais, Brazil)

\section{Cost of UltraHermetic Storage Systems}

The cost of portable UltraHermetic storage liners for insertion into conventional jute or woven polypropylene outer bags for mechanical protection vary widely based on volume, distribution chain, import costs and custom duties, if any. The least expense form with $69 \mathrm{~kg}$ capacity and intermediate permeability to oxygen of 50 $\mathrm{cc} / \mathrm{m}^{2} /$ day is for farm use only for many commodities; it is called the SuperGrainbag Farm ${ }^{\mathrm{TM}}$. In quantities of 10,000 (FOB factory) they cost $\$ 0.99$ each. For premium product storage and ultra-low permeability of 2 $\mathrm{cc} / \mathrm{m}^{2} /$ day, the factory quantity price starts at $\$ 1.10$ each. Retail prices in smaller quantities vary widely and are generally 2 to 3 times higher.

For multi-ton storage Cocoon prices (FOB factory) range from \$225/ton to $\$ 25 /$ ton for capacities between 5 tons and 1,000 tons, respectively, and have a 10 to 15 year life. The growing acceptance of UltraHermetic storage in 110 countries suggest that the available prices have been found cost-effective by a large range of users.

An Excel-based, user-input, cost-benefit analysis program to compare hermetic storage with alternative storage solutions is available without cost from GrainPro, Inc. (GrainPro, 2016) 


\section{Conclusion}

The problem of aflatoxin presence in food increasingly is being recognized as a major public health issue. In Africa, the African Union's PACA (Partnership for Aflatoxin Control in Africa) has led a Pan-African effort, with support from AGRA (Alliance for a Green Revolution in Africa) and from major foundations including the Rockefeller Foundation, to sensitize governments on the hazards of aflatoxins and the serious health problems they cause to their citizens, especially in the tropics.

Efforts to reduce aflatoxins through controlling their growth prior to harvest have produced encouraging improvements such as more resistant plant varieties, biological control such as AflaSafe, and breeding for increased plant resistance. However, farmers, city dwellers, and grain reserve agencies established to protect against large climatic swings suffer from enormous losses of stored grains contaminated by aflatoxins, especially if they are in hot, humid countries. This is why many look to UltraHermetic storage and solar dryers as better alternatives to conventional multi-month storage and traditional drying.

In June 2016 in Nairobi, Kenya, the Africa Strategic Grain Reserve Conference adopted the following resolution:

1 "Improvements in safe storage are possible - and necessary. Solutions exist that would make Africa self-sufficient in grains.

2 The adoption rate of modern storage technology is slower than the need."

The dominant food contamination problem in hot, humid climates continues to be exponential aflatoxin growth of grains during multi-month storage. UltraHermetic post-harvest storage is already in widespread use and recognized for its ability to dramatically reduce quantitative losses and quality deterioration, especially in tropical climates where annual storage losses can often be reduced to less than $1 \%$ from more than $25 \%$. This same storage technology also is available commercially to prevent dangerous exponential growth of aflatoxin contamination in grains and other food products grown and stored in these same environments.

\section{References}

Appaw (2016, January). An overview of mycotoxins in the food production chain and the impact on nutrition and health. Paper presented at the Multi-Sectoral Nutrition Strategy Global Learning \& Evidence Exchange, Accra, Ghana.

Bandyopadhyay, R., Ortega-Beltran, A., Akande, A., Mutegi, C., Atehnkeng, J., Kaptoge, L., Senghor, A., Adhikari, B., \& Cotty, P., (2016). Biological control of aflatoxins in Africa: current status and potential challenges in the face of climate change. World Mycotoxin Journal, 9(5), 771-789. http://dx.doi.org/10.3920/WMJ2016.2130

Bayer Crop Sciences, 2012, unpublished (GrainPro Document \#: PPT4051CG0314).

Borem, F., (2013). Handbook of Coffee Post-Harvest Technology. ISBN 978-0-9915721-0-6.

Borem, F., (2016). Postharvest technology and new packaging materials. PowerPoint presentation, SCAJ2016, Tokyo, Japan, 28-30 September, 2016.

Borem, F., Ribeiro, F., Figueiredo, L., Giomo, G., Fortunato, V., \& Isquierdo, E., (2013) Evaluation of the sensory and color quality of coffee beans stored in hermetic packaging. Journal of Stored Products Research, 52, 1-6. https://doi.org/10.1016/j.jspr.2012.08.004

De Bruin, T., Villers, P., \& Navarro, S., (2014). Worldwide development in Ultra Hermetic storage and solar drying techniques. $11^{\text {th }}$ International Working Conference on Stored Product Protection (IWCSPP), Chiang Mai, Thailand, 22-28 November, 2014

De Bruin, T., Villers, P., Wagh, A., \& Navarro, S., (2012). Worldwide Use of Hermetic Storage for the Preservation of Agricultural Products. Proceedings of the $9^{\text {th }}$ International Controlled Atmosphere \& Fumigation Conference. Antalya, Turkey.

FAO (2011). Situation analysis: improving food safety in the maize value chain in Kenya. Report prepared for Food and Agriculture Organization of the United Nations [FAO] by Prof. Erastus Kang'ethe. College of Agriculture and Veterinary Science, University of Nairobi.

Gong, Y., Hounsa, A., Egal, S., Turner, P., Sutcliffee, A., Hall, A., Cardwell, K., \& Wild, C., (2004). Postweaning exposure to aflatoxin results in impaired child growth: A longitudinal study in Benin, West Africa. Environmental Heal Perspectives, 112, 1334-1338. https://doi.org/10.1289/ehp.6954

Gou, B. (2013). Increase in aflatoxin concentration during storages of ground nuts in the farmers' fields. (Private communication). USDA-ARS, Tifton, GA. 
GrainPro (2016). Cost Benefit Analysis for Hermetic versus Non-hermetic Storage. GrainPro \#LT2263PV1111-3. Available on request thru sales@grainpro.com.

Lippai, A. (2016, Oct). (Private communication). OzonExtrade Kft., Budapest, Hungary.

Lunven, P. (1992). Maize in Human Nutrition. FAO Food and Nutrition Series 25, Rome, Italy.

Monda E., \& Alakonya A., (2016). A review of agricultural aflatoxin management strategies and emerging innovations in Sub-Saharan Africa. African Journal of Food, Agriculture, Nutrition and Development, 16(3). https://doi.org/10.18697/ajfand.75.ILRI11

Museveni, H. \& Yoweri, E. (2016). President Museveni opens $2^{\text {nd }}$ Partnership for Aflatoxin Control in Africa (PACA) Partnership Platform. Press Release No. 355/2016.

Navarro, H., Navarro, S., Finkelman, S. (2012). Hermetic and modified atmosphere storage of shelled peanuts to prevent free fatty acid and aflatoxin formation. Proceedings of the Conf. Int. Org. Biol. Integrated Control of Noxious Animals and Plants (IOBC). Work Group on Integrated Prot. Stored Prod. Bull. Volos, Greece.

Okoth, S., (2016). Improving the Evidence Base on Aflatoxin Contamination and Exposure in Africa: Strengthening the Agriculture-Nutrition Nexus. CTA Working Paper 16(13), 1-112.

Oladele, D., (2014). The effects of aflatoxins on animals. Partnership for Aflatoxin Control in Africa (PACA), (Meridian Institute, Washington, DC), Aflatoxin Partnership Newsletter, 2, 1-4.

Sabio, G.C. et al., (2006). Preservation of Mestizo 1 (PSB Rc72H) seeds using hermetic and low temperature storage technologies. Proc. $9^{\text {th }}$ Int. Working Conf. Stored Prod. Prot. Campinas, ABRAPOS, Sao Paulo, Brazil, 946-955.

Sudini, H., Rao, G., Gowda, C., Chandrika, R., Margam, V., Rahore, A., \& Murdock, L., (2014). Purdue Improved Crop Storage (PICS) bags for safe storage of groundnuts. Journal of Stored Products Research, 64, 133-138. http://dx.doi.org/10.1016/j.jspr.2014.09.002

Tumusiime, Rhoda Peace, (2016). Partnership for Aflatoxin Control in Africa (PACA), Press Release No $352 / 2016$.

Villers, P., (2013). Aflatoxins and Safe Storage. Frontiers in Microbiology, 5, 1-6.

Williams, J. H., (2011). Aflatoxin as a public health factor in developing countries and its influence on HIV and other diseases. Peanut Collaborative Research Support Program, University of Georgia. World Bank Report \#60371-AFR, 1-95.

Williams, J. H., Phillips, T. D., Jolly, P. E., Stiles, J. K., Jolly, C. M., \& Aggarwal, D. (2004). Human aflatoxicosis in developing countries: a review of toxicology, exposure, potential health consequences, and interventions. Am.J.Clin.Nutr. 80, 1106-1122.

Williams, S., Baributsa, D., \& Woloshuk, C., (2014). Assessing Purdue Improved Crop Storage (PICS) bags to mitigate fungal growth and aflatoxin contamination. Journal of Stored Products Research, 59, 190-196. http://dx.doi.org/10.1016/j.jspr.2014.08.003

Zorya, S., Morgan, N., \& Rios, L. D. (2011). Missing Food: The case of postharvest grain losses in Sub-Saharan Africa. World Bank Report \#60371-AFR. Washington, DC.

\section{Copyrights}

Copyright for this article is retained by the author(s), with first publication rights granted to the journal.

This is an open-access article distributed under the terms and conditions of the Creative Commons Attribution license (http://creativecommons.org/licenses/by/4.0/). 